\title{
Mast Cells Stimulated with Peptidoglycan from Staphylococcus aureus Augment the Development of Th1 Cells
}

\author{
Katsuhiko Matsui, Saeko Kanai, Manami Ikuta, Saki Horikawa \\ Department of Clinical Immunology, Meiji Pharmaceutical University, Tokyo, Japan. \\ Received, May 7, 2018; Revised, July 12, 2018; Accepted, July 13, 2018; Published, July 14, 2018.
}

\begin{abstract}
Background: The skin of patients with atopic dermatitis (AD) is superficially colonized by Staphylococcus aureus. We have previously found that percutaneous permeation of peptidoglycan (PEG) from $S$. aureus increases the number of mast cells in the dermis, as seen in skin lesions of AD patients. The purpose of the present study was to clarify the influence of PEG on T helper type 1 (Th1)/ T helper type 2 (Th2) cell development mediated by mast cells. Methods: Mast cells were induced by long-term culture of murine spleen cells in medium supplemented with tumor necrosis factor (TNF)- $\alpha$. Ovalbumin (OVA) peptide-pulsed mast cells were incubated with naïve Th cells in the presence or absence of PEG. Five days later, Th cells in the culture were stimulated with phorbol 12-myristate 13-acetate (PMA) and ionomycin, and Th1/Th2 cytokine production was investigated by enzyme-linked immunosorbent assay. Results: It was confirmed that the mast cells we obtained had surface expression of I-A ${ }^{\mathrm{d}}$, worked as antigen-presenting cells, and induced Th1 cell and Th2 cell development. The stimulation of mast cells with PEG enhanced the development of Th1 cells but not that of Th2 cells. The increase of Th1 cell development stimulated by PEG was associated with an increase in the expression of Notch ligand Delta 1 in the mast cells. Furthermore, treatment of mast cells with the macrolide antibiotic josamycin suppressed Th1 cell development and this was correlated with a reduction of both Delta 1 expression and interleukin (IL)-12 production in mast cells. Conclusions: Colonization of $S$. aureus on the lesioned skin of AD patients contributes to not only an increase in the number of mast cells but also Th1 cell development mediated by mast cells in the dermis and subsequent induction of chronic inflammation, which is characterized by up-regulation of the Th1 cytokine, interferon (IFN)- $\gamma$. Therefore, application of josamycin to the lesional skin of AD patients may provide relief from chronic inflammation mediated by mast cells.
\end{abstract}

\section{INTRODUCTION}

Atopic dermatitis (AD) is a chronic inflammatory skin disease with immunopathologic features that vary depending on the duration of the lesions. The chronic skin lesions of $\mathrm{AD}$ patients show an increased number of inflammatory cells such as mast cells, eosinophils, and mononuclear cells in the dermis and superficial colonization by Staphylococcus aureus (1). S. aureus can be isolated from $96 \%$ to $100 \%$ of skin lesions of $\mathrm{AD}$ patients, whereas the skin of only $0 \%$ to $10 \%$ of healthy individuals are colonized by this organism $(2,3)$. We have also found previously that the rate of detection of $S$. aureus on the lesional skin of $\mathrm{AD}$ patients was higher than that on the non-lesional skin of these patients (3). Furthermore, the bacterial cell count of $S$. aureus on the lesional skin of AD patients was significantly higher than that on the skin of healthy individuals or the non-lesional skin of $\mathrm{AD}$ patients. However, there was no significant difference in the rates of detection of $S$. aureus producing superantigenic exotoxin, which is believed to be the most important pathogenic factor, on the lesional and non-lesional skin of $\mathrm{AD}$ patients.

Gram-positive bacterial cell walls are composed of highly cross-linked peptidoglycan (PEG) decorated to a variable extent with teichoic acid polymers. The latter are also linked to plasma membrane phospholipids, of which lipoteichoic acid (LTA) and PEG are the major surface components $(4,5)$. Gram-positive bacteria contain no lipopolysaccharide (LPS), and LTA and/or PEG are thought to be major inflammatory products in their cell walls. Therefore, we hypothesized that LTA and/or PEG from $S$. aureus may be pathogenic factors that are more important than superantigenic exotoxins in $\mathrm{AD}$ patients $(6,7)$. In a previous study, we found that percutaneous application of PEG induced higher numbers of

Corresponding Author: Katsuhiko Matsui, Ph. D., Department of Clinical Immunology, Meiji Pharmaceutical University, 2-522-1 Noshio, Kiyose, Tokyo 204-8588, Japan; E-mail: kmatsui@my-pharm.ac.jp 
mast cells in murine skin, as is seen in AD patients (8). Furthermore, recent findings have indicated that mast cells express major histocompatibility complex (MHC) class II molecules and work as antigen-presenting cells (APCs) $(9,10)$. Therefore, antigen presentation by mast cells may play an important role in induction of the $\mathrm{T}$ helper type 1 (Th1) and/or $\mathrm{T}$ helper type 2 (Th2) immune response in skin lesions of $\mathrm{AD}$ patients. In the present work, we attempted to confirm whether PEG derived from $S$. aureus influences antigen presentation by mast cells.

\section{MATERIALS AND METHODS}

\section{PEG}

PEG derived from $S$. aureus was obtained from Fluka (Buchs SG, Switzerland). The PEG was reconstituted in phosphate-buffered saline (PBS), $\mathrm{pH} \mathrm{7.4}$, at a concentration of $1 \mathrm{mg} / \mathrm{mL}$, and sonicated for $1 \mathrm{~h}$ before use.

\section{Mice}

Specific-pathogen-free BALB/c (wild type) mice and DO 11.10 TCR Tg mice (ovalbumin (OVA) 323-339-specific I-A ${ }^{\mathrm{d}}$-restricted TCR-transgenic mice) were obtained from Japan SLC (Hamamatsu, Japan) and The Jackson Laboratory (Bar Harbor, Maine, USA), respectively, and used at the age of 6 to 8 weeks. They were housed in plastic cages with sterilized paper bedding in a clean, air-conditioned room at $24{ }^{\circ} \mathrm{C}$ and allowed free access to a standard laboratory diet and water. All procedures performed on the mice were in accordance with the Guidelines of the Animal Care and Use Committee of Meiji Pharmaceutical University, Tokyo.

\section{Generation of Mast Cells from Mouse Spleen Cells}

Mast cells were induced by long-term (16 days) culture of mouse spleen cells in RPMI 1640 medium with L-glutamine (Sigma, St. Louis, MO, USA) containing 10\% fetal bovine serum (Sigma), $25 \mathrm{mM}$ Hepes (Sigma), $100 \mathrm{U} / \mathrm{mL}$ penicillin, and $100 \mu \mathrm{g} / \mathrm{mL}$ streptomycin (Gibco RBL, Grand Island, NY, USA) (RPMI 10) supplemented with $10 \mathrm{ng} / \mathrm{mL}$ tumor necrosis factor (TNF)- $\alpha$ (R\&D Systems, Minneapolis, MN, USA), as described by $\mathrm{Hu}$ et al. (11). To obtain purified mast cells, the mast cells in the culture were separated from dead cells and small lymphocytes by Histopaque-1077 (Sigma) and further expanded in RPMI 10 supplemented with $20 \mathrm{ng} / \mathrm{mL}$ interleukin (IL)-3
(Peprotech, Rocky Hill, NJ, USA) and $20 \mathrm{ng} / \mathrm{mL}$ IL-4 (Peprotech) for 1 week.

\section{Detection of Cell Surface I-A ${ }^{\mathrm{d}}$ Antigen on Mast Cells}

Mast cells were stained with phycoerythrin-conjugated anti-I- $\mathrm{A}^{\mathrm{d}}$ monoclonal antibody (Clone 34-5-3S; mouse IgG2a) (Cedarlane, Ontario, Canada), and cell surface I-A ${ }^{\mathrm{d}}$ antigen was detected by flow cytometry (FCM).

\section{Th1 and Th2 Cell Development by Mast Cells}

Mast cells were adjusted to $1 \times 10^{5}$ cells $/ \mathrm{mL}$ in RPMI 10 and incubated in the presence or absence of PEG $(10 \mu \mathrm{g} / \mathrm{mL})$ and josamycin $(10 \mu \mathrm{M}$; provided by Astellas Pharma Inc., Tokyo, Japan) for $18 \mathrm{~h}$ at $37^{\circ} \mathrm{C}$ in a humidified atmosphere with $5 \% \mathrm{CO}_{2}$, and then washed before use. Next, $\mathrm{T}$ helper (Th) cells were separated from DO 11.10 TCR Tg mouse spleen cells using an EasySep Negative Selection Mouse CD4 ${ }^{+} \mathrm{T}$ Cell Enrichment Kit (StemCell Technologies, Vancouver, BC, Canada) and then treated with mouse anti-CD62L monoclonal antibody (clone lam1-116, IgG2a) (1 $\mu \mathrm{g}$ per $1 \times 10^{6}$ cells; Santa Cruz Biotechnology, Santa Cruz, CA, USA) in RPMI 10 for $1 \mathrm{~h}$ on ice. The Th cells that had been reacted with anti-CD62L antibody were then purified using a CELLection $^{\mathrm{TM}}$ Pan Mouse IgG Kit (Invitrogen Dynal AS, Oslo, Norway), and used as naïve Th cells. The naïve Th cells $\left(5 \times 10^{5}\right.$ cells $\left./ \mathrm{mL}\right)$ were cultured with the above mast cells $\left(1 \times 10^{5}\right.$ cells $/ \mathrm{mL}$ ) in the presence of $30 \mathrm{nM}$ OVA peptide (323-ISQAVHAAHAEINEAGR-339; obtained from Operon Biotechnologies, Tokyo, Japan) for 5 days at $37^{\circ} \mathrm{C}$. The cells were then stimulated with $50 \mathrm{ng} / \mathrm{mL}$ phorbol 12-myristate 13-acetate (PMA) (Sigma) and $500 \mathrm{ng} / \mathrm{mL}$ ionomycin (Sigma) for 24 $\mathrm{h}$ at $37^{\circ} \mathrm{C}$. The cell supernatants were finally removed and tested for production of interferon (IFN)- $\gamma$ and IL-4 using enzyme-linked immunosorbent assay (ELISA) kits (R\&D Systems).

\section{Reverse Transcription-Polymerase Chain Reaction (RT-PCR) Assay}

In order to determine the levels of mRNA expression for various cell surface molecules, mRNA was extracted from mast cells $\left(1 \times 10^{5}\right.$ cells $)$ using a Dynabeads ${ }^{\circledR}$ mRNA DIRECT ${ }^{\mathrm{TM}}$ Micro Kit (Life Technologies, Oslo, Norway). Then, the cDNA was synthesized from the mRNA using a first-strand cDNA synthesis kit (GE Healthcare UK Ltd., Little Chalfont, Buckinghamshire, UK). 
Polymerase chain reaction (PCR) was performed using the following primers: $\beta$-actin (540 bp) $5^{\prime}$ primer, 5'-GTGGGCCGCTCTAGGCACCAA-3' and $3^{\prime}$ primer, 5'-CTCTTTGATGTCACGCACGATTTC-3';

$\begin{array}{llll}\text { CD80 } & (312 & \text { bp }) \quad 5^{\prime} & \text { primer, }\end{array}$
5'-GAAGACCGAATCTACTGGCA-3' and 3' primer, 5'-GGAAGCAAAGCAGGTAATCC-3'; $\begin{array}{lllll}\text { CD86 } & \text { (302 } & \text { bp) } & 5^{\prime} & \text { primer, }\end{array}$ 5'-AGCCTGAGTGAGCTGGTAGT-3' and 3' primer, 5'-CCTGTTACATTCTGAGCCAG-3';

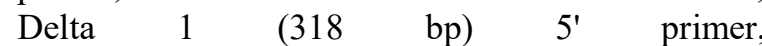
5'-TGCACTGACCCAATCTGTCT-3' and $3^{\prime}$ primer, 5'-CTCACAGTTGGCACCTGTAT-3';

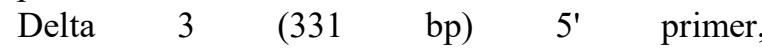
5'-CTACTGTGAAGAGCCTGATG-3' and 3' primer, 5'-ACAGACATAGGCAGAGTCAG-3'; $\begin{array}{lllll}\text { Delta } 4 & (307 & \text { bp }) & 5^{\prime} & \text { primer, }\end{array}$ 5'-TCACCAGACTGAGCTACTCT-3' and 3' primer, 5'-ATGCTGCAGGTGCCATGGAT-3';

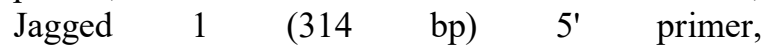
5'-ATCCGAGTGACCTGTGATGA-3' and 3' primer, 5'-TTGGTCTCACAGAGGCACTG-3'; $\begin{array}{lllll}\text { Jagged } 2 & (300 & \text { bp }) & 5^{\prime} & \text { primer, }\end{array}$ 5'-GCTGTGATGAGAACTACTAC-3' and 3' primer, 5'-TCTCACAGTCACAGTGCCAG-3'; T-cell immunoglobulin and mucin domain-containing protein (TIM)-4 (304 bp) $5^{\prime}$ primer, 5'-GTCCAGTTTGGTGAAGTGTC-3' and 3' primer, 5'-ACGTGGTCACTGCTGTACTG-3'. Each PCR was performed using a GeneAmp PCR System 9700 (Perkin-Elmer, Norwalk, CT, USA) in $25 \mu \mathrm{L}$ reaction mixture comprising $1.5 \mu \mathrm{L}$ cDNA, $200 \mu \mathrm{M}$ deoxynucleotide triphosphate mixture, 400 $\mathrm{nM}$ each PCR primer and $25 \mathrm{U} / \mathrm{mL}$ Ex Taq DNA polymerase (Takara, Shiga, Japan). The reaction conditions were as follows: one 4-min cycle at 94 ${ }^{\circ} \mathrm{C}, 35$ cycles comprising $45 \mathrm{~s}$ at $94{ }^{\circ} \mathrm{C}, 45 \mathrm{~s}$ at 61 ${ }^{\circ} \mathrm{C}$ and 2 min at $72{ }^{\circ} \mathrm{C}$, followed by one 7 -min cycle at $72{ }^{\circ} \mathrm{C}$, and the PCR products were separated on a $2 \%$ agarose gel containing ethidium bromide.

\section{Quantification of IL-12 p70 Production by Mast Cells}

Mast cells were adjusted to $1 \times 10^{5}$ cells $/ \mathrm{mL}$ in RPMI 10 and stimulated with $10 \mu \mathrm{g} / \mathrm{mL}$ PEG in the presence or absence of $10 \mu \mathrm{M}$ josamycin for $18 \mathrm{~h}$ at $37^{\circ} \mathrm{C}$ in a humidified atmosphere with $5 \% \mathrm{CO}_{2}$. The mast cells were washed and subsequently incubated at $1 \times 10^{5}$ cells $/ \mathrm{mL}(0.2 \mathrm{~mL} /$ well $)$ in 96-well plates. The culture supernatants were collected after incubation for $48 \mathrm{~h}$, and the IL-12 p70 concentration was measured using an ELISA kit for quantification of murine IL-12 p70 (R\&D Systems).

\section{STATISTICAL ANALYSIS}

Data were expressed as means $( \pm$ SD), and differences between means were analyzed by Student's $t$ test or one-way analysis of variance (ANOVA), followed by Tukey's multiple comparison test. Differences at $P<0.05$ were considered to be statistically significant.

\section{RESULTS}

Antigen-Presenting Ability of Mast Cells Derived from Murine Spleen Cells

There is still apparent controversy as to whether mast cells express MHC class II molecules and function as APCs (10). The results of FCM analysis showed that mast cells induced by long-term culture of murine spleen cells expressed MHC class II molecule, I-A ${ }^{\mathrm{d}}$ antigen on their surface (Figure 1). This suggested that the mast cells obtained in the present study might function as antigen-presenting cells. Next, therefore, we confirmed whether or not the mast cells had ability to present antigen to naïve helper $\mathrm{T}$ (Th) cells. As shown in Figure 2, naïve Th cells were activated by mast cells only in the presence of OVA peptide as an antigen, and secreted IFN- $\gamma$ as a Th1 cytokine and IL-4 as a Th2 cytokine into the culture supernatant.

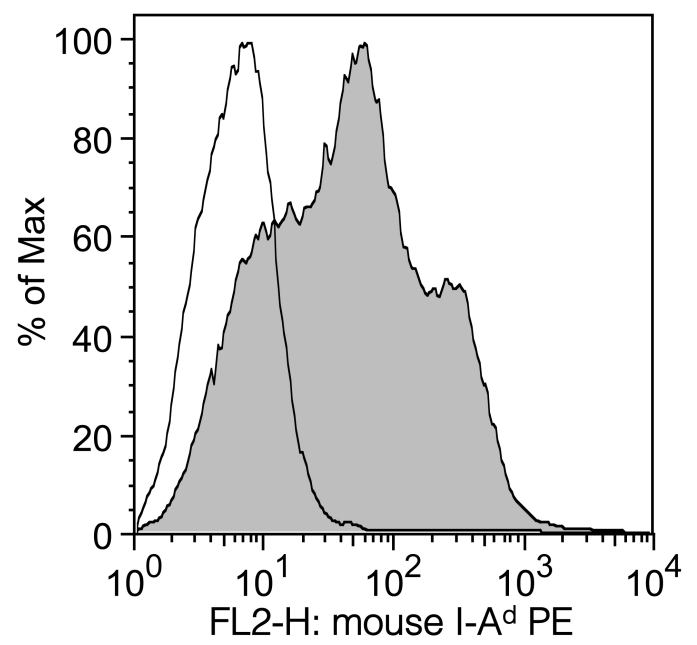

Figure 1. Expression of $I-A^{d}$ antigen on the surface of mast cells. Mast cells were generated from mouse spleen cells, stained with phycoerythrin-conjugated anti-I-A $\mathrm{A}^{\mathrm{d}}$ monoclonal antibody and analyzed by FCM. The data shown are representative of four independent experiments. 

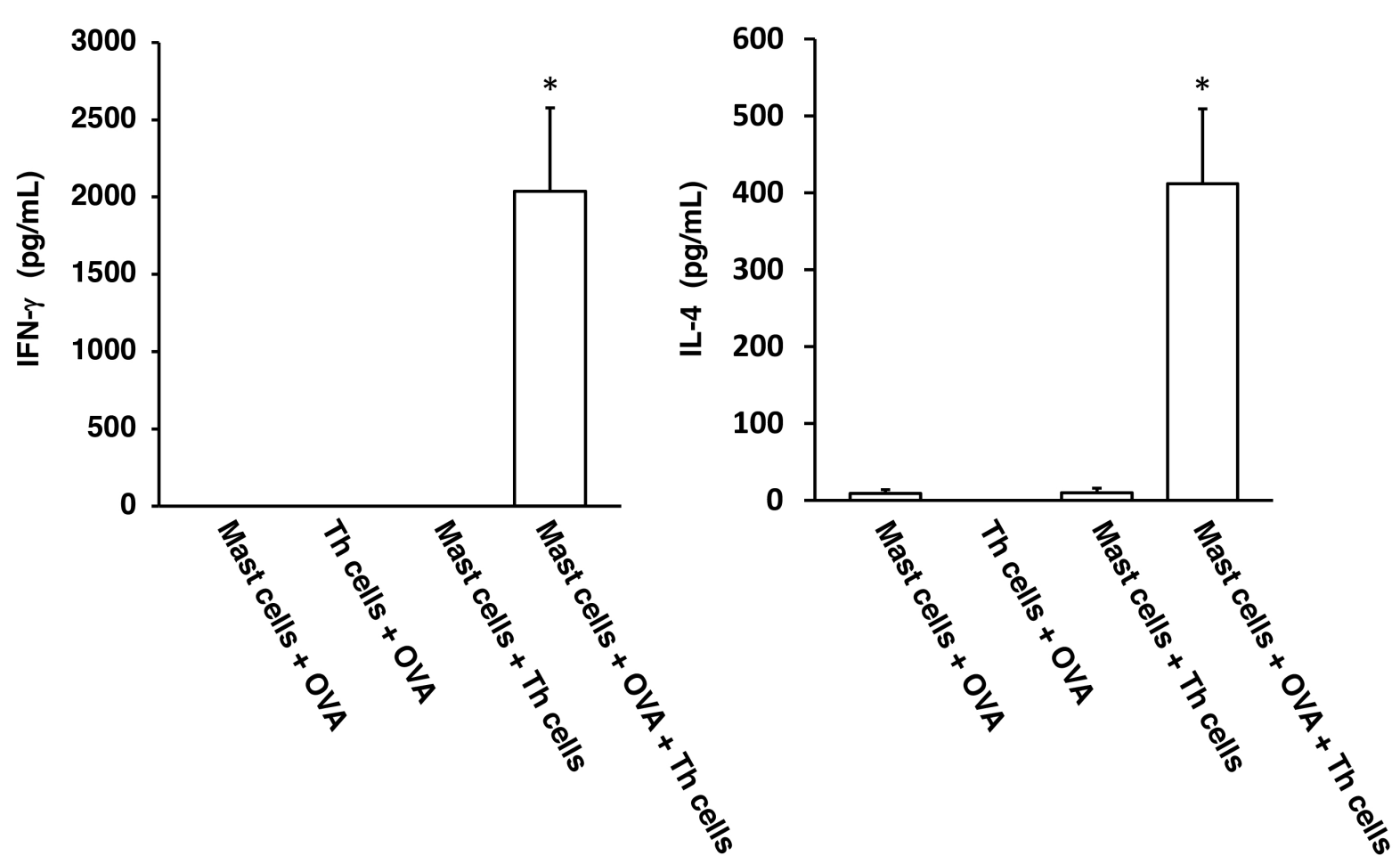

Figure 2. Detection of the antigen-presenting ability of mast cells. Mast cells were incubated for 5 days in the presence of OVA peptide and naïve Th cells. After 5 days, the activated Th cells were stimulated with PMA and ionomycin for $24 \mathrm{~h}$, and the IFN- $\gamma$ and IL-4 concentrations in the culture supernatants were determined by ELISA. The results are expressed as means $\pm \mathrm{SD}(\mathrm{n}=6) . * P<0.01$ versus Mast cells + Th cells.

\section{Effects of PEG on Th1 Cell and Th2 Cell Development through Mast Cells}

Mast cells were stimulated with PEG for $18 \mathrm{~h}$, then cultured with naïve $\mathrm{Th}$ cells in the presence of OVA peptide. As shown in Figure 3A, mast cells stimulated with PEG markedly enhanced the production of IFN- $\gamma$ from the activated Th cells, but their IL-4 production was not changed.

Subsequently, in order to clarify the mechanism responsible for the PEG-induced increase of IFN- $\gamma$ production through mast cells, mast cells were incubated for $18 \mathrm{~h}$ in the presence or absence of PEG, and expression of cell surface molecules in mast cells was confirmed by RT-PCR. As shown in Fig. 3B, the results of RT-PCR indicated that mRNAs for CD80, CD86, Delta 1, Delta 4 and Jagged 2, but not for Delta 3, Jagged 1 and TIM-4, were expressed spontaneously in mast cells and predicted the presence of those molecules on their surface. Furthermore, mast cells treated with PEG showed enhanced expression of Delta 1 mRNA. However, the expression of other mRNAs was not influenced by PEG.

\section{Effect of Josamycin on the PEG-Induced Enhancement of Th1 Cell Development through Mast Cells}

Our previous study had shown that Langerhans cells (LCs) treated with josamycin induced down-regulation of both Th1 cell and Th2 cell development (12). Furthermore, josamycin showed a superior anti-bacterial effect on clinical isolates of $S$. aureus. These findings suggested that josamycin acts on both superficial $S$. aureus and epidermal LCs of AD patients, conferring highly beneficial effects. Accordingly, we investigated the effect of josamycin on the PEG-induced augmentation of Th1 cell development through mast cells. As shown in Figure 4A, josamycin significantly suppressed the PEG-induced augmentation of IFN- $\gamma$ to normal levels without affecting the level of IL-4 production.

On the other hand, the augmentation of Delta 1 mRNA expression by PEG treatment of mast cells was suppressed to normal levels by josamycin (Fig. 4B). Furthermore, treatment of mast cells with PEG enhanced their IL-12 p70 production, and this was significantly inhibited by josamycin (Fig. 4C). 
(A)

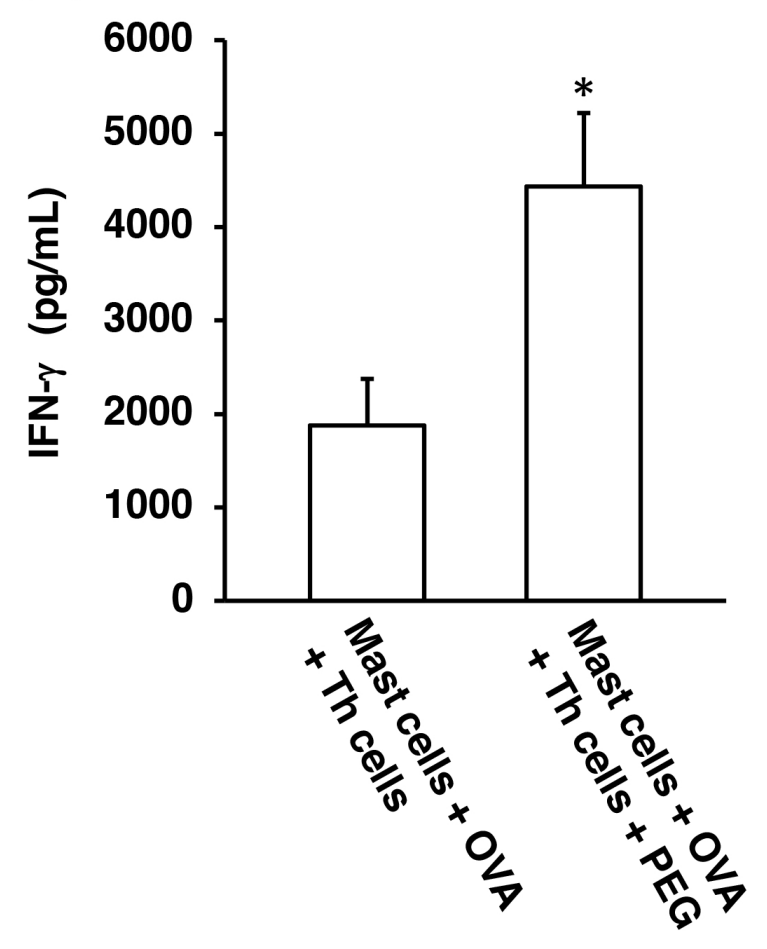

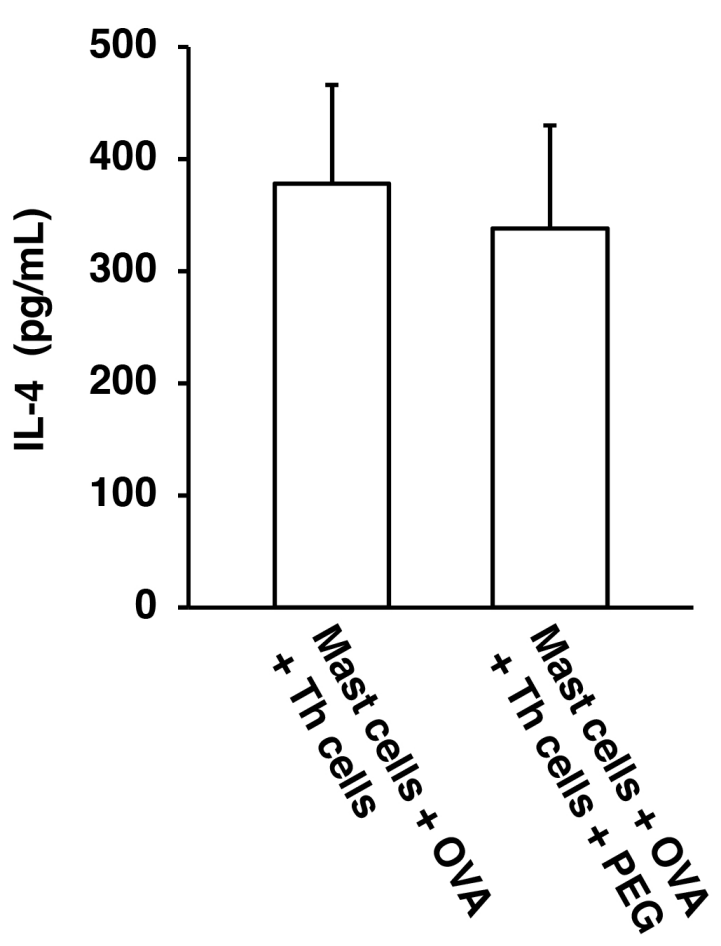

(B)

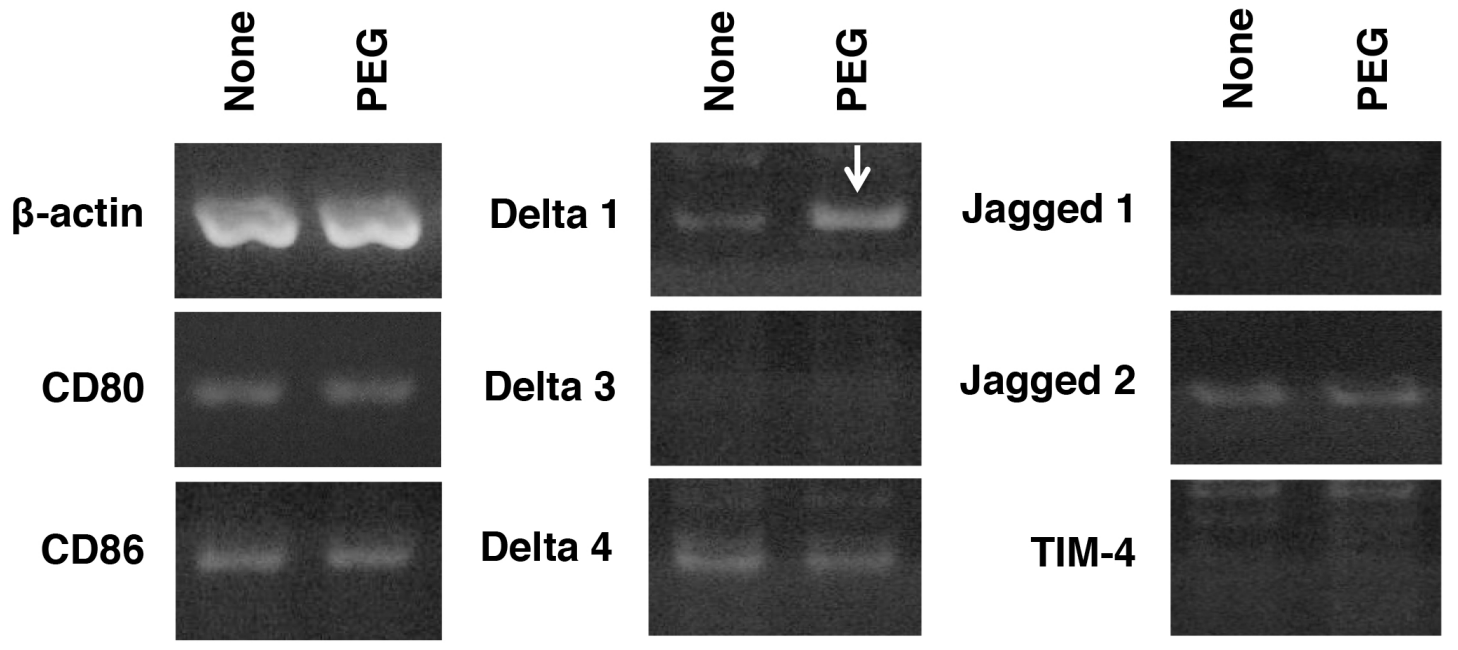

Figure 3. Effects of PEG on Th1 cell and Th2 cell development mediated by mast cells. (A) Mast cells were stimulated with PEG for $18 \mathrm{~h}$. The mast cells were washed and subsequently incubated for 5 days in the presence of OVA peptide and naïve Th cells. After 5 days, the activated Th cells were stimulated with PMA and ionomycin for $24 \mathrm{~h}$, and the IFN- $\gamma$ and IL-4 concentrations in the culture supernatants were determined by ELISA. The results are expressed as means $\pm \mathrm{SD}(\mathrm{n}=6) .{ }^{*} P<0.01$ versus without PEG. (B) Mast cells were stimulated with PEG for $18 \mathrm{~h}$. Cytoplasmic mRNA was extracted from mast cells, reverse-transcribed and amplified by PCR using primer sets for $\beta$-actin, CD80, CD86, Delta 1, Delta 3, Delta 4, Jagged 1, Jagged 2 and TIM-4. The data shown are representative of four independent experiments. 
(A)

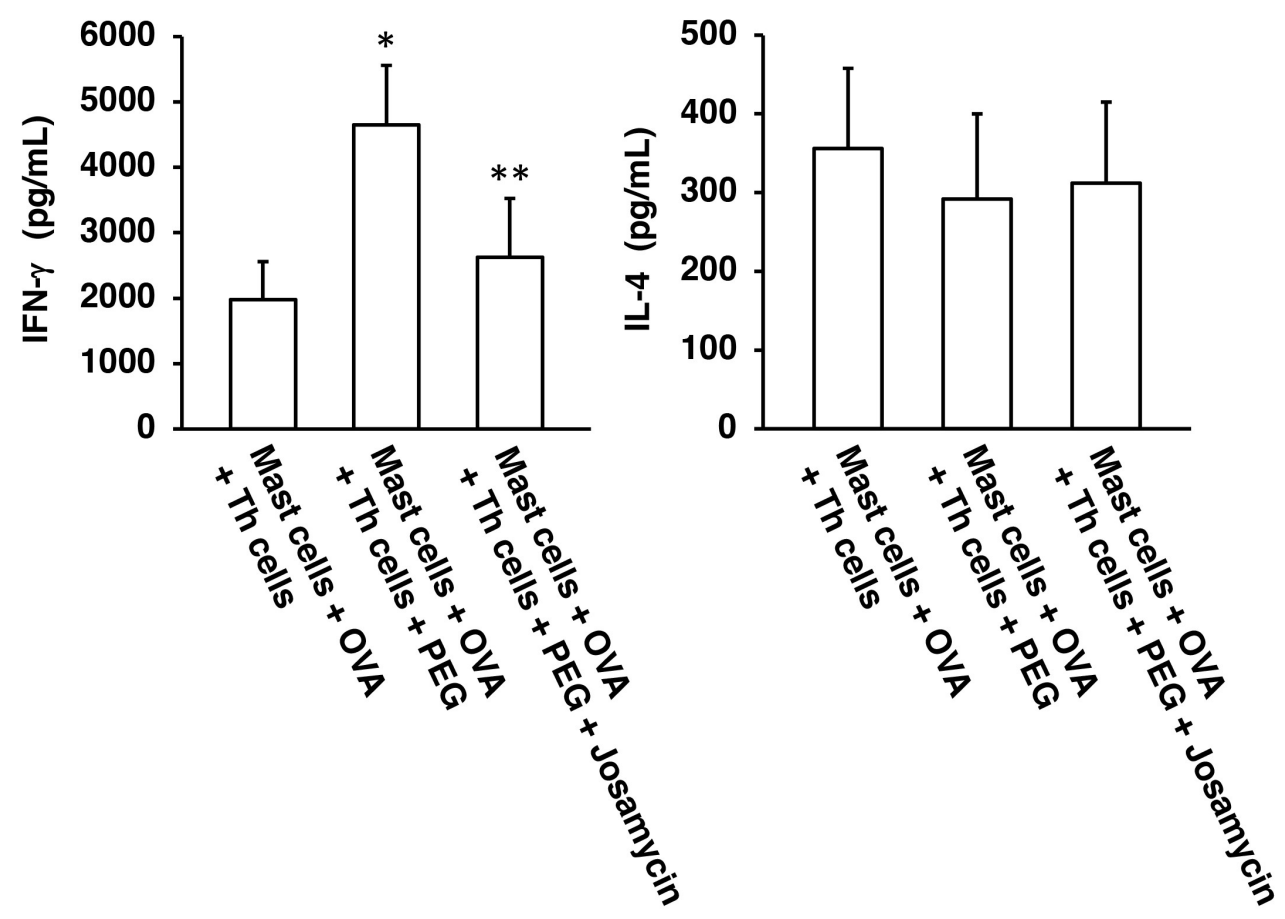

(B)

(C)

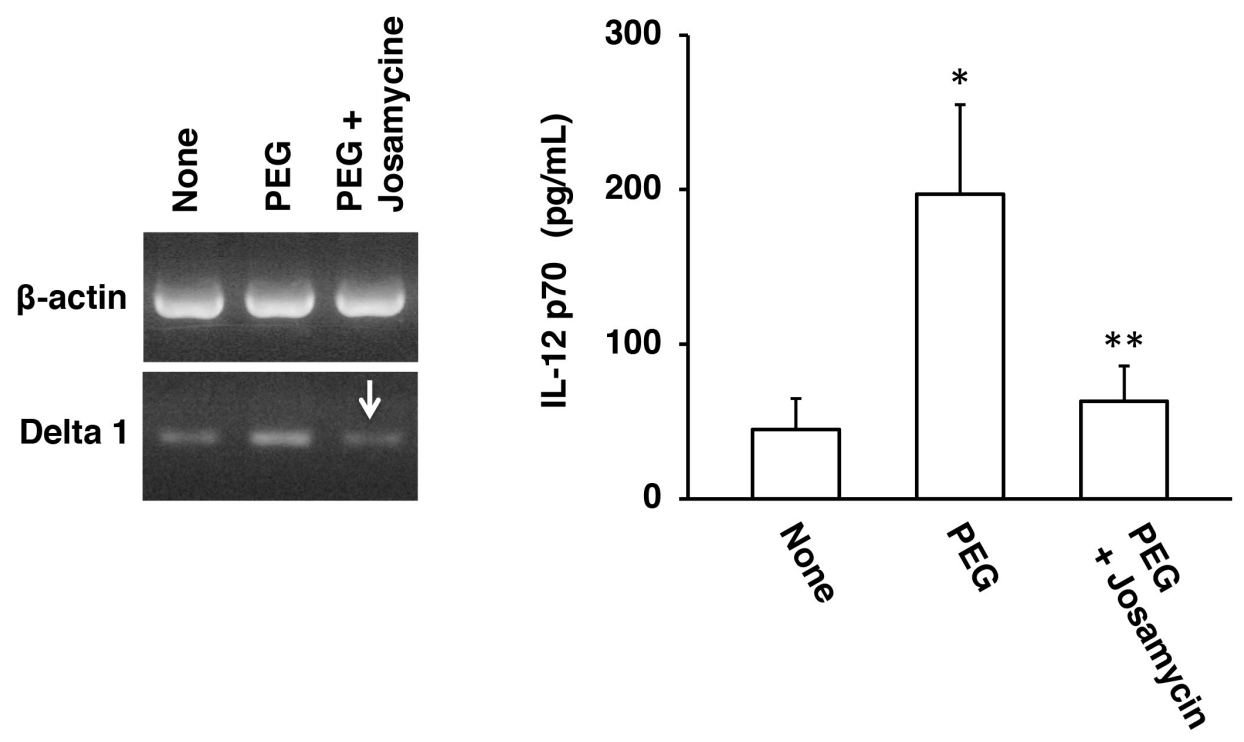

Figure 4. Effect of josamycin on the PEG-induced increase of Th1 cell development mediated by mast cells. (A) Mast cells were stimulated with PEG for $18 \mathrm{~h}$ in the presence or absence of josamycin. The mast cells were washed and subsequently incubated for 5 days in the presence of OVA peptide and naïve Th cells. After 5 days, the activated Th cells were stimulated with PMA and ionomycin for $24 \mathrm{~h}$, and the IFN- $\gamma$ and IL-4 concentrations in the culture supernatants were determined by ELISA. The results are expressed as means $\pm \mathrm{SD}(\mathrm{n}=6) . * P<0.01$ versus Mast cells + OVA + Th cells, ${ }^{* *} P<0.05$ versus Mast cells + OVA + Th cells + PEG. (B) Mast cells were stimulated with PEG for $18 \mathrm{~h}$ in the presence or absence of josamycin. Cytoplasmic mRNA was extracted from the mast cells, reverse-transcribed and amplified by PCR using primer sets for $\beta$-actin and Delta 1 . The data shown are representative of four independent experiments. (C) Mast cells were stimulated with PEG for $18 \mathrm{~h}$ in the presence or absence of josamycin. The mast cells were then washed and subsequently incubated for $48 \mathrm{~h}$. The culture supernatants were then assayed for IL-12 p70 production using ELISA. The results are expressed as means $\pm \mathrm{SD}(\mathrm{n}=6)$. ${ }^{*} P<0.01$ versus non-treatment, $* * P<0.01$ versus $\mathrm{PEG}$ treatment. 


\section{DISCUSSION}

The lesioned skin of $\mathrm{AD}$ patients contains increased numbers of mast cells (13-15), which release inflammatory chemical mediators, such as histamine, leukotrienes, and prostaglandins, upon IgE-mediated stimulation with specific allergens. Furthermore, mast cells produce a wide variety of cytokines, suggesting their active participation in the late-phase reaction and chronic stage of inflammation $(16,17)$. We previously reported that murine skin to which PEG from $S$. aureus had been applied showed an increased number of mast cells relative to skin that had received only PBS (8). This finding appeared to explain the role of $S$. aureus colonization on the skin of $\mathrm{AD}$ patients, and suggested that mast cells as APCs may augment Th1/Th2 cell development in the dermis. However, the influence of PEG on Th1/Th2 cell development through mast cells was not clarified.

Our present study showed that mast cells obtained by long-term culture of murine spleen cells in the presence of TNF- $\alpha$ expressed MHC class II molecules. Expression of MHC class II molecules on the surface of mast cells is necessary for them to function as APCs. Only when OVA peptide was added as an antigen did mast cells activate naive Th cells to become Th1 cells and Th2 cells, and induce production of the Th1 cytokine, IFN- $\gamma$ and the Th2 cytokine, IL-4, respectively. These results confirmed our expectation that the mast cells we had obtained possessed antigen-presenting ability. Similar results were obtained in another experiment using OVA whole protein as an antigen (data not shown). This result is also important as it shows that the mast cells possessed antigen processing ability. Furthermore, PEG derived from $S$. aureus significantly enhanced the development of Th1 cells, but not that of Th2 cells. Since PEG itself did not directly activate naïve $\mathrm{Th}$ cells (data not shown), it was thought that this effect would appear through mast cells. Although PEG is well known to be a toll-like receptor 2 (TLR2) agonist (18), TLR2 is known to exist on mouse and human mast cells $(19,20)$ and we also detected expression of TLR2 mRNA in our mast cells (data not shown), thus predicting that TLR2 would be present on their surface. Therefore, signaling through TLR2 on mast cells would be associated with the increase of Th1 cell development.

To clarify the mechanisms of this Th1/Th2 immune balance, expression of cell surface molecules on mast cells was confirmed by RT-PCR.
mRNAs for CD80, CD86, Delta 1, Delta 4 and Jagged 2, but not for Delta 3, Jagged 1 and TIM-4, were expressed spontaneously in mast cells, thus predicting the presence of those molecules on their surface. When mast cells were stimulated with PEG, an increase of Delta 1 mRNA expression was observed. In mammals, four Notch receptors Notch 1-4 - and five Notch ligands - Delata1, Delta 3, Delta 4, Jagged 1 and Jagged 2 - have been identified (21). Amsen et al. (22) have presented evidence that different Notch ligands expressed on APCs instruct Th1/Th2 cell development in mice, and have concluded that Th1 adjuvant induces Th1 cell development through expression of Delta members in APCs, while Th2 adjuvant induces $\mathrm{Th} 2$ cell development through expression of Jagged members in APCs. Therefore, these results suggest that Th1 cell development is mediated by Delta 1 and Delta 4 on mast cells and that $\mathrm{Th} 2$ cell development is mediated by Jagged 2 on mast cells. TIM-4 is expressed by dendritic cells in lymphoid organs, and its ligand, TIM-1, is expressed by $\mathrm{T}$ cells. These molecules have been found to be critical regulators of Th2 cell development (23). Although Th2 cell development mediated by LCs is associated with TIM-4 expression (12), it seems that mast cells do not require its expression on their cell surface to induce Th2 cell development. Subsequently it was clarified that the further increase of Th1 cell development triggered by PEG could be explained by augmentation of Delta 1 expression on mast cells.

In our previous study, we demonstrated that the 16-membered ring macrolide antibiotic josamycin suppressed the development of both Th1 cells and Th2 cells through LCs and had a superior antibacterial effect on $S$. aureus derived from $\mathrm{AD}$ patients. In the present study, we found that josamycin down-regulated the PEG-induced augmentation of Th1 cell development through mast cells. The results of RT-PCR showed that josamycin suppressed the PEG-induced increase of Delta 1 mRNA expression in mast cells and that this suppressive effect extended to the PEG-induced increase of IL-12 p70 production from mast cells. IL-12 p70 has been shown to be a critical regulator of Th1 cell development both in vitro and in vivo (24).

The data from this study showed that mast cells expressing MHC class II molecules on their surface work as APCs and that mast cells stimulated with PEG from S. aureus enhance Th1 cell development. This result may explain the mechanism of 
induction of chronic inflammation in $\mathrm{AD}$ patients, in which a Th1 immune response is observed in addition to a Th2 immune response (25). Since the skin of most AD patients shows superficial $S$. aureus colonization and barrier disruption due to a decrease of filaggrin (26), a bacterial product such as PEG would easily penetrate the skin. The PEG would increase the number of mast cells in the dermis according to the chronicity of skin lesions (8), stimulate those mast cells, and cause inflammation based on a Th1 cytokine response. Furthermore, our previous study showed that $S$. aureus strains isolated from the lesional skin of $\mathrm{AD}$ patients were particularly susceptible to josamycin in comparison with gentamicin (12), which is used widely in Japan in combination with steroids for topical application in $\mathrm{AD}$ patients. Therefore, application of josamycin to the skin appears to be a unique approach in that it would not only exert an antibacterial effect against $S$. aureus but would also control Th1/Th2 cell development through not only LCs but also mast cells (12). Thus, topical administration of josamycin might be a promising new therapeutic strategy for both acute and chronic $\mathrm{AD}$ lesions with $S$. aureus infection. However, since the possible development of antibiotic resistance is one of the most worrying problems associated with josamycin treatment, periodic inspection to detect josamycin-resistant bacteria in the skin lesions of $\mathrm{AD}$ patients would be necessary, and if such bacteria were detected, josamycin would need to be withdrawn immediately.

Previous reports have not fully explained the role of $S$. aureus on mast cells in the skin lesions of $\mathrm{AD}$ patients. As the density of $S$. aureus in $\mathrm{AD}$ patients exceeds at least $1 \times 10^{7}$ organisms $/ \mathrm{cm}^{2}$ of lesioned skin (27), sustained $S$. aureus colonization would lead to an elevated concentration of PEG, thus affecting the dermal mast cells.

\section{CONCLUSIONS}

Our present results suggest that $S$. aureus colonization may play a critical role in perpetuating the skin tissue inflammation in $\mathrm{AD}$ through excessive induction of Th1 cell development mediated by PEG-stimulated mast cells. Therefore, a combination of antimicrobial treatment and therapy for APCs such as mast cells and LCs in at least a subgroup of $\mathrm{AD}$ patients, irrespective of whether they show clinical signs of superinfection, may be considered as a new therapeutic strategy for AD.

\section{ACKNOWLEDGEMENTS}

This work was supported by JSPS KAKENHI

Grant Number 17K08469.

\section{CONFLICTS OF INTEREST}

The authors have no conflicts of interest to declare.

\section{REFERENCES}

1. Leung DY, Boguniewicz M, Howell MD, Nomura I, Hamid QA. New insights into atopic dermatitis. J Clin Invest, 2004; 113: 651-657.

2. Guzik TJ, Bzowska M, Kasprowicz A, Czerniawska-Mysik G, Wójcik K, Szmyd D, Adamek-Guzik T, Pryjma J. Persistent skin colonization with Staphylococcus aureus in atopic dermatitis: relationship to clinical and immunological parameters. Clin Exp Allergy, 2005; 35: 448-455.

3. Matsui K, Nishikawa A, Suto H, Tsuboi R, Ogawa H. Comparative study of Staphylococcus aureus isolated from lesional and non-lesional skin of atopic dermatitis. Microbiol Immunol, 2000; 44: 945-947.

4. Lambert PA, Hancock IC, Baddiley J. Occurrence and function of membrane teichoic acids. Biochim Biophys Acta, 1977; 472: 1-12.

5. Fischer W. Bacterial phosphoglycolipids and lipoteichoic acids, in Hannah DJ (ed), Handbook of Lipid Research, Plenum, New York, pp 123-234, 1989.

6. Matsui K, Motohashi R, Nishikawa A. Cell wall components of Staphylococcus aureus induce interleukin-5 production in patients with atopic dermatitis. J Interferon Cytokine Res, 2000; 20: 321-324.

7. Matsui K, Nishikawa A. Lipoteichoic acid from Staphylococcus aureus induces Th2-prone dermatitis in mice sensitized percutaneously with an allergen. Clin Exp Allergy, 2002; 32: 783-788.

8. Matsui K, Nishikawa A. Percutaneous application of peptidoglycan from Staphylococcus aureus induces an increase in mast cell numbers in the dermis of mice. Clin Exp Allergy, 2005; 35: 382-387.

9. Kambayashi T, Allenspach EJ, Chang JT, Zou T, Shoag JE, Reiner SL, Caton AJ, Koretzky GA. Inducible MHC class II expression by mast cells supports effector and regulatory $\mathrm{T}$ cell activation. $\mathrm{J}$ Immunol, 2009; 182: 4686-4695.

10. Nakano N, Nishiyama C, Yagita H, Koyanagi A, Akiba H, Chiba S, Ogawa H, Okumura K. Notch signaling confers antigen-presenting cell functions on mast cells. J Allergy Clin Immunol, 2009; 123: 74-81.

11. Hu Z-Q, Kobayashi K, Zenda N, Shimamura T. Tumor necrosis factor- $\alpha-$ and 
interleukin-6-triggered mast cell development from mouse spleen cells. Blood, 1997; 89: 526-533.

12. Matsui K, Tamai S, Ikeda R. Effects of macrolide antibiotics on Th1 cell and Th2 cell development mediated by Langerhans cells. J Pharm Pharm Sci, 2016; 19: 357-366.

13. Mikhail GR, Miller-Milinska A. Mast cell population in human skin. J Invest Dermatol, 1964; 43: 249-254.

14. Mihm MCJ, Soter NA, Dvorak HF, Austen KF. The structure of normal skin and the morphology of atopic eczema. J Invest Dermatol, 1976; 67: 305-312.

15. Damsgaard TE, Olesen AB, Sørensen FB, Thestrup-Pedersen K, Schiøtz PO. Mast cells and atopic dermatitis: stereological quantification of mast cells in atopic dermatitis and normal human skin. Arch Dermatol Res, 1997; 289: 256-260.

16. Harvima IT, Horsmanheimo L, Nankkarinen A, Horsmanheimo M. Mast cell proteinases and cytokines in skin inflammation. Arch Dermatol Res, 1994; 287: 61-67.

17. Bradding P. Human mast cell cytokines. Clin Exp Allergy, 1996; 26: 13-19.

18. Re F, Strominger JL. Toll-like receptor 2 (TLR2) and TLR4 differentially activate human dendritic cells. J Biol Chem, 2001; 276: 37692-37699.

19. Supajatura V, Ushio H, Nakao A, Okumura K, Ra C, Ogawa H. Protective roles of mast cells against enterobacterial infection are mediated by Toll-like receptor 4. J Immunol, 2001; 167: 2250-2256.

20. McCurdy JD, Olynych TJ, Maher LH, Marshall JS. Cutting edge: distinct Toll-like receptor 2 activators selectively induce different classes of mediator production from human mast cells. J Immunol, 2003; 170:1625-1629.

21. Artavanis-Tsakonas S, Rand MD, Lake RJ. Notch signaling: cell fate control and signal integration in development. Science, 1999; 284: 770-776.

22. Amsen D, Blander JM, Lee GR, Tanigaki K, Honjo T, Flavell RA. Instruction of distinct CD4 T helper cell fates by different Notch ligands on antigen-presenting cells. Cell, 2004; 117: 515-526.

23. Ruiter B, Shreffler WG. The role of dendritic cells in food allergy. J Allergy Clin Immunol, 2012; 129: 921-928.

24. D'Andrea A, Ma X, Aste-Amezaga M, Paganin C, Trinchieri G. Stimulatory and inhibitory effects of interleukin (IL)-4 and IL-13 on the production of cytokines by human peripheral blood mononuclear cells: priming for IL-12 and tumor necrosis factor $\alpha$ production. J Exp Med, 1995; 181: 537-546.

25. Herz U, Bunikowski R, Renz H. Role of $\mathrm{T}$ cells in atopic dermatitis: new aspects on the dynamics of cytokine production and the contribution of bacterial superantigens. Int Arch Allergy Immunol, 1998; 115: 179-190.

26. Brown SJ, McLean WH. One remarkable molecule: filaggrin. J Invest Dermatol, 2012; 132: 751-762.

27. Leyden JJ, Marples RR, Klingman AM.
Staphylococcus aureus in the lesions of atopic dermatitis. Br J Dermatol, 1974; 90: 525-529. 